\title{
Fear, Peer Pressure, or Encouragement: Identifying Levers for Nudging Towards Healthier Food Choices in Multi-Cultural Singapore
}

\author{
Kum-Seong Wan 2, Bryan Jun-Keat Choo 1,3, Kwok-Fong Chan ${ }^{1}$, Joshua Yi Yeo ${ }^{1}$, Clare Shu-Lin Tan ${ }^{2}$, Boon-Kiat \\ Quek 2, Samuel Ken-En Gan 1,3,4, \\ 1 Antibody \& Product Development Lab, EDDC - BII, Agency for Science, Technology and Research \\ (A*STAR), Singapore 138672; bryan.choo@my.jcu.edu.au (B.J.-K.C.); kwokfong29@gmail.com (K.-F.C.); \\ joshua_yeo@eddc.a-star.edu.sg (J.Y.Y.) \\ 2 Social \& Cognitive Computing, Institute of High Performance Computing, Agency for Science, Technology \\ and Research (A*STAR), Singapore 138632; kswan@ihpc.a-star.edu.sg (K.-S.W.); tanslc@ihpc.a-star.edu.sg \\ (C.S.-L.T.); quekbk@ihpc.a-star.edu.sg (B.-K.Q.) \\ 3 Department of Psychology, James Cook University, Singapore 387380 \\ 4 APD SKEG Pte Ltd, Singapore 439444 \\ * Correspondence: samgan@apdskeg.com; samuel.gan@jcu.edu.au; Tel.: +65 64070584
}

\begin{abstract}
With roots beyond behavioural economics to psychology, nudges can be applied for influencing healthy behaviours such as food choice and portions to decrease obesity for better public health outcomes. However, the effectiveness of the type of nudges are contentious with conflicting literature. In this pilot study, we conducted a 23-day study surveying the food choices that included portion, locus of control, demographic data, and psychological measures of personality, perceived stress, narcissism, regulatory focus, food choice motive and dietary restraint, with the participants given four intervention conditions of 12 instant messaging sent every two days through WhatsApp. The messages were either factual (control), focused on consequences, through social comparison, or persuasive. Running over the COVID19 pandemic, 17 participants completed the full surveys showing significant effects between the experimental conditions with the psychological parameters except for diet confidence and extraversion and conscientiousness, as well as cognitive restraint. We found BMI and waistline measurements to be suitable measurements, with promising results from the fear and social comparison nudges for food-related behaviours and exercise. Our pilot findings have implications to the use of nudges upon which future studies investigating psychological factors can build on.
\end{abstract}

Keywords: Nudges; Diet; Healthy Living; Instant Messaging; Digital Interventions

\section{Introduction}

The 2017 Nobel Prize in Economic Sciences was awarded to Richard H. Thaler for his contributions to behavioural economics. Thaler's research, built upon work that were subjects of the 1978 and 2002 prizes [1], highlighted the role of nudges. This was followed by decades of research and interest by governments all over the world, not surprisingly notably in the area of tax collection [2]. The notion of nudges has roots beyond behavioural economics, including psychology where Pavlovian conditioning [3], biopsychological habituation of sea slugs [4], and conscious and unconscious behavioural priming [5] have been continually pursued and incorporated into modern applications. These include the study of subliminal priming in social engineering effects, or lack thereof [6]. While controversial, new ideas for influencing behaviour such as the use of sonic devices to prevent teen loitering [7], or blue lights at Japanese train stations to deter suicide attempts [8] continue to emerge. Regardless of their aim or methodology, the science underlying nudging 
have shown promise, keeping it a topic of interest by paternalistic authorities $[9,10]$ and the public health domain.

Over the years, psychological studies underlying influencing effects have investigated the use of fear [11] in health [12,13], encouraging messages [14]; as well as persuasion through social/peer-pressure [15] among others. There remains conflicting literature on the underlying psychological traits that determine the susceptibility or resistance to the varying types of nudges. Thus, the mechanism would need to be better investigated, highlighted by a meta-analysis finding no statistically significant differences between gain- and loss-framed messages for a wide variety of behaviours [16]. At the edge of psychological factors underlying nudging is environmental psychology, where the immediate surrounding can have stimuli that can affect the psyche or effectiveness of the stimuli. Such inclusion have been observed in the use of music to reduce anxiety [17], disrupt or support learning and academic performance [18], and even in food and beverages retail spending [19].

For positive behavioural changes [20] towards sustainability [21]; education [22]; public health [23-26] as well as interest by corporate processes [27], and even vaccination [28] as in the ongoing COVID19 pandemic, much remains to be investigated on the parameters that influence effectiveness.

Apart from the more immediate consequences of nudging towards better hygiene and vaccination in the pandemic, there are many other long-term issues that behavioural changes can alleviate in public health. The longstanding co-morbidities from poor lifestyle such as diabetes, hypertension [29], cardiac risks [30-32], etc. are notably linked to obesity [33].

Obesity is a global problem for wealthy nations. In multi-cultural Singapore, officials reported that the median Body Mass Index (BMI) score had risen from 22.23 in 2001 to 23.15 in 2016, approaching the upper limit of the recommended healthy BMI range [34], and potentially pushing the obesity rate in the country to 15 percent by 2025. This problem, like that of other countries, come predominantly from increased daily calorie intake, where in Singapore, the increase went from an average of 1,929 kcal in 1998 to 2,470 kcal in 2018 [35,36] compared to the recommended daily intake of 2,200 and 1,800 kcal for adult males and females, respectively. A contributing factor to this is the consumption of larger food portion sizes due to increased variety and rising affluence fuelling more snacking and meals. Moreover, eating beyond satiation is still an ingrained cultural habit in Asia. Yet another contributor is sugar intake; where adults in Singapore consume an average of 60 grams of sugar daily above the recommended daily intake of 25 grams, with sweetened drinks being the single largest source, followed by confectionery and desserts [36,37].

Based on these factors, a significant number of behavioural choices needs to be addressed. Traditionally, legal regulations (e.g. ban), monetary measures (e.g. taxation), or public awareness campaigns would often be the go-to mitigatory measures, however they are often coercive in nature, limited in effectiveness or may require much resources to implement and maintain [38]. Such issues pave the way for behavioural nudges to play an important role, where apart from the commonly used fear, encouragement of peer pressure, more subtle nudge techniques, such as goal settings, social modelling, persuasion, etc., have been applied across a variety of behaviours with small to moderate effect sizes [39-41]. Interestingly, a previous meta-analysis showed that nudges based on 'shaping knowledge' technique elicited higher effectiveness, followed by 'comparison of behaviour', 'natural consequences' and 'self-belief' [42]. With smartphones being more ubiquitous in our everyday lives and even in psychological research [43-46], there is avenue of utilizing smartphones as well as smartphone-dependent wearables such as the Apple Watch, Samsung Watch, etc. to administer nudges. In fact, studies that employed such methodology to change behaviours have reported favourable outcomes [47-49]. 


\subsection{Hypotheses Formation}

Singapore is a good locale to study the effects of behavioural nudging on food health behaviour given her multicultural backdrop that can deeply influence dietary choices [50], and that nudges are already applied in areas such as taxation [51] and corporate processes [52]. In fact, Singapore is reportedly one of the most compliant countries to COVID-19 pandemic measures [53]. In the same spirit as these recent studies where behavioural nudges have shown some efficacy, the present study was conceived with the goal of shedding light on the prospects of applying behavioural nudge strategies on food choice, such as messages based on fear (of negative health consequences), constructive encouragement, and social pressure (such as social comparison), with these being delivered digitally over a smartphone. The hypotheses include:

Hypothesis 1: Individuals receiving nudge messages (all types) would have lower body measurements after intervention than before while those receiving control messages would have no difference.

Hypothesis 2: Individuals receiving nudge messages (all types) would have improved food consumption behaviour after intervention than before while those receiving control messages would have no difference.

Hypothesis 3: Individuals receiving nudge messages based on constructive encouragement would have higher diet confidence and diet persistence after intervention than before while those receiving messages based on fear, social pressure, and those in the control condition would experience negligible differences.

\section{Materials and Methods}

\subsection{Research Design}

The study adopts a single-blind randomized controlled trial design with a control condition ("control") and three experimental conditions ("health consequences", "behaviour substitution", and "social comparison") corresponding to the three techniques (Figure 1). The outcomes were measured at three time points: pre-intervention (baseline), midintervention, and post-intervention (Figure 2A). This design allowed us to detect significant changes in outcomes across the intervening time points and between the conditions. Ethics approval was granted by the Agency for Science, Technology, and Research (A*STAR), Singapore Institutional Review Board under number 2019-007 and the protocols and procedure adhered to for the whole study, with informed consent from the participants. The study was conducted in compliance of prevailing ethical guidelines. 


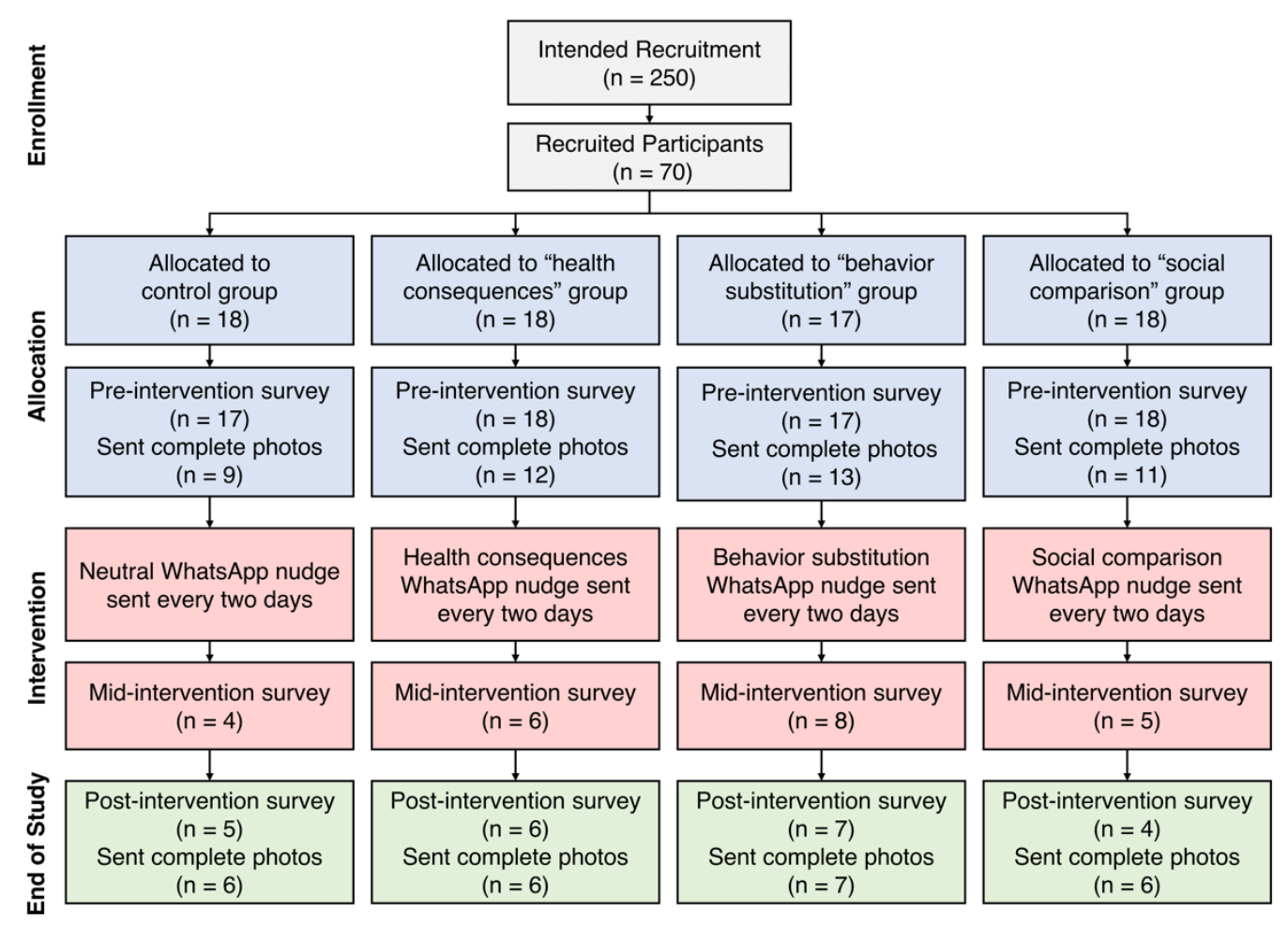

Figure 1. Study and participant flow.

\subsection{Participants}

Volunteers for the study were recruited between June 2019 and June 2020 through convenience sampling in various settings that included social media platforms. Festive periods (e.g., Chinese New Year, Ramadan) were avoided to prevent anomalous effects due to feasting or fasting. A priori power analysis of mixed-design ANOVA composing of 4 between-conditions and minimally 2 within-measurements with power $(1-\beta)=0.80$, $\alpha=0.05$, and effect size $=0.25$ was conducted using $G^{*}$ Power, suggesting a minimum sample size of 136 . Accounting for a $50 \%$ participant dropout rate, the study aimed to recruit at least 250 participants with the following criteria: (a) ages 21 years and above, (b) healthy with no known medical condition, (c) familiar with and actively using WhatsApp as an instant messaging service, (e) currently working or residing in Singapore, (f) proficient in English language, and $(\mathrm{g})$ not undergoing any existing medical-directed food or physical activity programmes. Participation was strictly voluntary, and subjects did not receive monetary reimbursements for their participation. This would help reduce the impact of selection biases. 
A

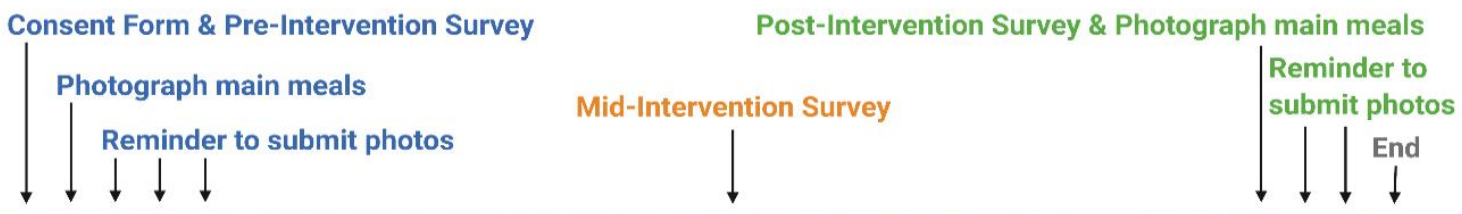

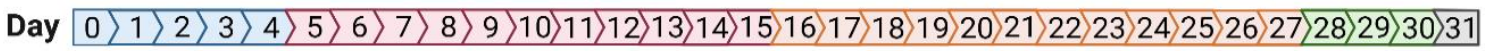

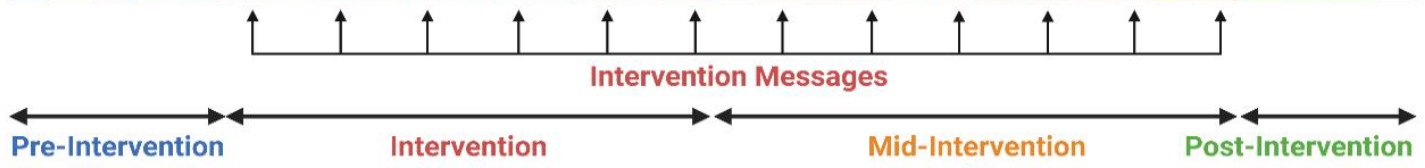

B
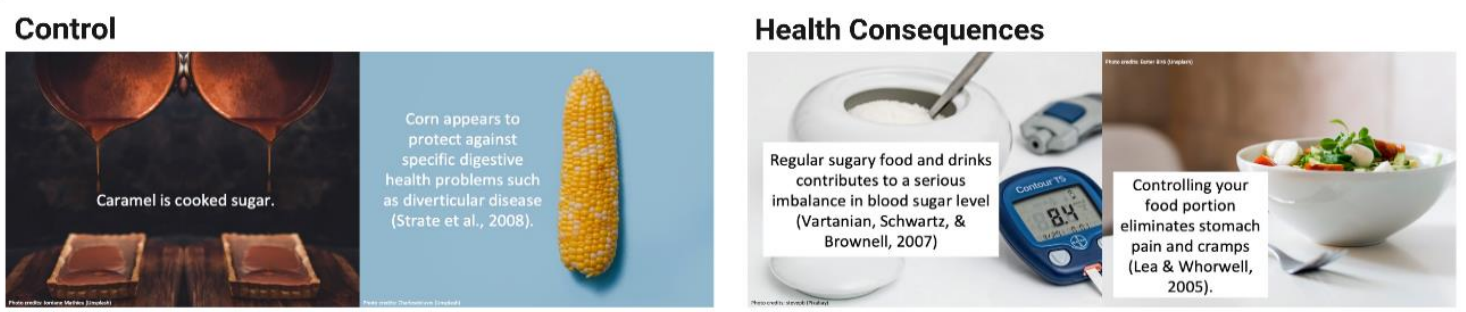

Behaviour Substitution
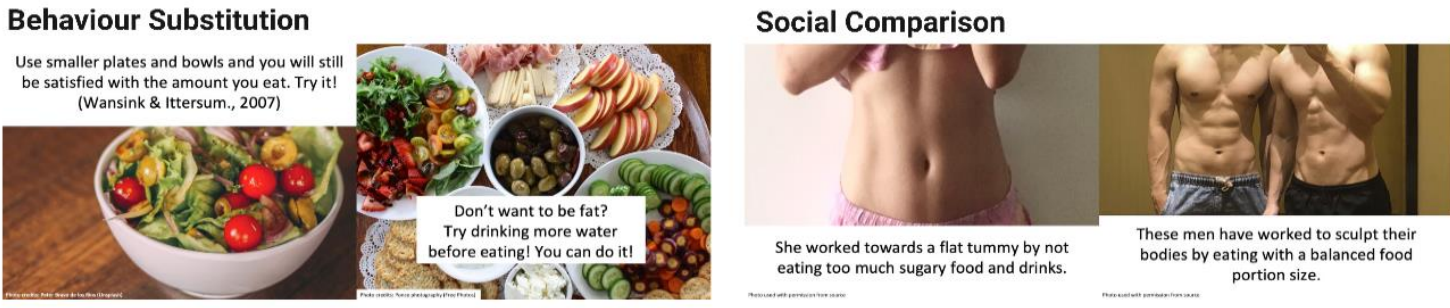

Figure 2. (A) Timeline for the administration study procedure and intervention. (B) Examples of nudge messages used in the respective four study conditions: Control, Health Consequences, Behaviour Substitution, Social Comparison. See Supplementary Table S3 for the detailed list.

\subsection{Nudge-Message Development}

The concept behind intervention design utilizes the smartphone as the means for a direct message-based behavioural change intervention, with messages designed based on the Behavioural Change Wheel framework [54], and delivered at particular time points to participants. The goal of behaviour nudging in this case, was to promote a reduction of food portion sizes, as well as intake of sugary foods and drinks. Given its prevalent use in Singapore, the WhatsApp instant messaging service ("WhatsApp") was chosen as the medium for delivering these messages. Four sets of behavioural change messages comprising images or illustrations and text captions (Table S3) were designed, corresponding to three different behaviour change techniques [55] and a control condition. With a total of four study conditions, a total of 12 messages were developed (Figure 2B). Each pair of image illustrations with accompanying text captions would present a different health or nutritional information snippet, contextualised according to the nudge techniques involved in the conditions they were based on, including neutral facts ("control"); scare tactics ("health consequences"); constructive encouragement ("behavioural substitution"); and peer pressure ("social comparison"). Specifically, messages in the "control" condition described the nutritional information of various food items as neutral facts method. Messages in the "health consequences" condition highlighted the health risks and negative consequences of not consuming smaller food portions, restricting sugar intake, or not exercising, as scare tactics. In contrast, message in the "behaviour substitution" condition applied constructive encouragement by suggesting actions or alternatives that would prompt individuals to consume smaller food portions, restrict sugar intake, or exercise more. Lastly, messages in the "social comparison" condition provided exemplars of 
physically fit and healthy individuals to prompt these social comparisons including comparison with peers.

\subsection{Survey Measurements}

Participants were asked to complete an online survey at pre-, mid-, and post-intervention time points after the initial informed consent (see Supplementary Table S1). The pre-intervention survey assessed participants' body measurements, food consumption behaviours, preferred food portion, sugary food and drinks intake, diet confidence and diet persistence, as well as internal locus of control with respect to health. It also gathered socio-demographic features and assessed various psychological constructs including personality, perceived stress, narcissism, regulatory focus, food choice motive, and dietary restraint. Both the mid- and post-intervention surveys contained similar sets of questions, but excluded the socio-demographic questions and psychological measures. These two surveys further gathered participants' perception of message validity.

Body measurements were assessed through self-reported height, weight, and waistline measurements. The body mass index (BMI) was then calculated from the height and weight. Food consumption behaviours and preferences were assessed in two ways. Preferred portion sizes were assessed through a locally adapted food portion selection task [56], while a specific subscale of the dietary practice questionnaire [35] gathered self-reports on the frequency that sweetened drinks (e.g., tea and coffee), as well as desserts and snacks, were consumed in the past week. Diet confidence and diet persistence were assessed respectively through single-item questions, namely "If you are to go on a diet now, how confident are you that you will succeed?" and "If you are to go on a diet now, how long do you think you can sustain it?". Health internal locus of control was assessed with the corresponding subscale of the multidimensional health locus of control scale [57]. Lastly, validity for the nudge messages were assessed through single-item questions, namely " $D o$ you agree that the messages sent to you during the study help you to manage your diet or eating habits" and "Do you agree that you feel healthier after the intervention?" respectively.

Socio-demographic characteristics surveyed include gender, ethnicity, age group, and household income level. Personality was assessed based on five factor model of personality with the Mini-IPIP scale [58]. Perceived stress was assessed with the Perceived Stress Scale [59]. Narcissism was assessed with the Single-Item Narcissism Scale [60]. Promotion and prevention regulatory focus was assessed with the Regulatory Focus Scale [61]. Food choice motive was assessed with the subscales for the health and weight factors from the Food Choice Questionnaire [62]. Lastly, dietary restraint was assessed with the uncontrolled eating, cognitive restraint, and emotional eating factors of the Thee Factor Eating Questionnaire [63].

Participants were also asked to take a photo of every meal that they had in a day and submit them through WhatsApp at the pre- and post-intervention time points (Supplementary Table S2). Their meal photos would be processed using the APD Areametric App [64] which would estimate the average food portion sizes of the meals that they had consumed in a day at pre- and post-intervention timepoints. This was used for the analysis of their actual food portion consumption.

\subsection{Procedures}

Recruited participants were asked to visit the online survey [46] for the research information sheet and to acknowledge it and the provide their informed consent before completing the pre-intervention survey. Mobile numbers were also collected for the sending of nudge messages via WhatsApp after the participants were assigned to the one of the four study conditions on a rolling basis.

Two days after a participant had signed up, a WhatsApp message would be sent to remind them to take a top-down photo of their meals in a day (with a Singapore $\$ 1$ coin placed next to it for automatic area calibration by the APD Areametric app). For the next 
three days, an automated script would send messages to participants over WhatsApp at 7 a.m. local time daily, to remind them to submit photos of their meals.

Following the photo request, intervention messages (across the various conditions) were sent over 23 days in a similar manner. Every two days at 7 a.m., an automated script would send a nudge message over WhatsApp to the study participants based on their assigned study conditions. In this way, each participant would receive 12 nudge messages by the end of the intervention period. On Day 16, study participants were prompted to complete the mid-intervention survey online hosted on the same platform.

A day after the end of the intervention period, WhatsApp messages would be sent to prompt study participants to complete the post-intervention survey online, and to take the final meal photos of the meals the participants had, for that day. As with the earlier prompts, reminder messages for the photos would be sent for the next three days at 7 a.m. local time. On the last day, a WhatsApp message would be sent to the participants to announce the end of the study and thank them for their participation. No further messages would be sent beyond that point.

\section{Results}

\subsection{Participants}

70 participants were recruited for this study (Figure 1) between October 2019 to June 2021). 70, 23, and 22 of the participants completed the pre-, mid-, and post-intervention surveys respectively, with only 17 completing all three surveys. Of the participants, 45 and 25 submitted their meal photos at pre- and post-intervention time points respectively with 25 of them submitting at both time points. In total, only 17 participants completed all three surveys and submitted their meal photos at both pre- and post-intervention time points.

Table 1 summarizes the socio-demographic characteristics of the participants based on gender, ethnicity, age group and household income level by study conditions. 33 (47\%) participants were female while $37(53 \%)$ were male. Ethnically, 55 (79\%) participants were Chinese while $8(11 \%), 4(6 \%)$ and $3(4 \%)$ were Indian, Malay and others respectively. 17 (24\%) participants were in the 21 - 24 age group while $35(50 \%), 12(17 \%), 5(7 \%)$ and 1 (1\%) were in the 25 - 34, 35 - 44, 45 - 54 and 55 - 64 age group respectively. Lastly, 8 (11\%) participants indicated a household income of $\leq \$ 2,000$ while $12(17 \%), 12(17 \%), 10(14 \%)$, $10(14 \%), 6(9 \%)$ and $12(17 \%)$ indicated a household income of $\$ 2,001-\$ 4,000, \$ 4,001$ $\$ 6,000, \$ 6,001-\$ 8,000, \$ 8,001-\$ 10,000, \$ 10,001-\$ 15,000$ and $>\$ 15,000$.

Table 1. Socio-demographic Characteristics of Participants.

\begin{tabular}{lccccc}
\hline & \multicolumn{5}{c}{$n(\%)$} \\
\cline { 2 - 5 } & Overall & Control & $\begin{array}{c}\text { Health conse- } \\
\text { quences }\end{array}$ & $\begin{array}{c}\text { Behaviour } \\
\text { substitution }\end{array}$ & $\begin{array}{c}\text { Social compar- } \\
\text { ison }\end{array}$ \\
\hline Gender & $33(47.14)$ & $7(41.18)$ & $8(44.44)$ & $8(47.06)$ & $10(55.56)$ \\
Memale & $37(52.86)$ & $10(58.82)$ & $10(55.56)$ & $9(52.94)$ & $8(44.44)$ \\
\hline Ethnicity & & & & \\
Chinese & $55(78.57)$ & $14(82.35)$ & $14(77.78)$ & $14(82.35)$ & $13(72.22)$ \\
Indian & $8(11.43)$ & $2(11.76)$ & $2(11.11)$ & $0(0.00)$ & $4(22.22)$ \\
Malay & $4(5.71)$ & $1(5.88)$ & $1(5.56)$ & $1(5.88)$ & $1(5.56)$ \\
Others & $3(4.29)$ & $0(0.00)$ & $1(5.56)$ & $2(11.76)$ & $0(0.00)$ \\
\hline Age group & & & & & \\
$21-24$ & $17(24.29)$ & $4(23.53)$ & $4(22.22)$ & $5(29.41)$ & $4(22.22)$ \\
$25-34$ & $35(50.00)$ & $9(52.94)$ & $10(55.56)$ & $8(47.06)$ & $8(44.44)$ \\
$35-44$ & $12(17.14)$ & $2(11.76)$ & $4(22.22)$ & $2(11.76)$ & $4(22.22)$ \\
$45-54$ & $5(7.14)$ & $2(11.76)$ & $0(0.00)$ & $1(5.88)$ & $2(11.11)$ \\
$55-64$ & $1(1.43)$ & $0(0.00)$ & $0(0.00)$ & $1(5.88)$ & $0(0.00)$
\end{tabular}




\begin{tabular}{lccccc}
$\geq 65$ & $0(0.00)$ & $0(0.00)$ & $0(0.00)$ & $0(0.00)$ & $0(0.00)$ \\
\hline Household income & & & & & \\
$\leq \$ 2,000$ & $8(11.43)$ & $2(11.76)$ & $3(16.67)$ & $2(11.76)$ & $1(5.56)$ \\
$\$ 2,001-\$ 4,000$ & $12(17.14)$ & $4(23.53)$ & $5(27.78)$ & $2(11.76)$ & $1(5.56)$ \\
$\$ 4,001-\$ 6,000$ & $12(17.14)$ & $5(29.41)$ & $2(11.11)$ & $3(17.65)$ & $2(11.11)$ \\
$\$ 6,001-\$ 8,000$ & $10(14.29)$ & $0(0.00)$ & $3(16.67)$ & $3(17.65)$ & $4(22.22)$ \\
$\$ 8,001-\$ 10,000$ & $10(14.29)$ & $3(17.65)$ & $1(5.56)$ & $2(11.76)$ & $4(22.22)$ \\
$\$ 10,001-\$ 15,000$ & $6(8.57)$ & $0(0.00)$ & $2(11.11)$ & $4(23.53)$ & $3(16.67)$ \\
$>\$ 15,000$ & $12(17.14)$ & $3(17.65)$ & $(16.67)$ & $1(5.8)$ & \\
\hline
\end{tabular}

\subsection{Descriptive Statistics}

Table 2 presents the descriptive statistics of the outcome measures by study conditions and intervention time points. Additionally, the Cronbach alpha scores for the preferred food portion for consumption were $0.87,0.89$ and 0.94 for pre-, mid-, and postintervention respectively, while for the health internal locus of control they were $0.72,0.86$ and 0.83 for pre-, mid-, and post-intervention respectively. Table 3 presents the descriptive statistics of the psychological measures including their Cronbach alpha scores.

Table 2. Descriptive Statistics of Outcome Measures.

\begin{tabular}{|c|c|c|c|c|c|c|c|c|c|}
\hline & \multicolumn{3}{|c|}{ Pre-intervention } & \multicolumn{3}{|c|}{ Mid-intervention } & \multicolumn{3}{|c|}{ Post-intervention } \\
\hline & $n$ & $M$ & $S D$ & $n$ & $M$ & $S D$ & $n$ & $M$ & $S D$ \\
\hline \multicolumn{10}{|l|}{ Control } \\
\hline BMI & 17 & 23.07 & 2.89 & 4 & 23.71 & 2.98 & 5 & 22.24 & 1.48 \\
\hline Waistline $(\mathrm{cm})$ & 17 & 78.57 & 8.75 & 4 & 85.82 & 14.38 & 5 & 74.46 & 6.34 \\
\hline Preferred food portion for consumption & 14 & 5.37 & 1.64 & 3 & 5.77 & 1.07 & 5 & 5.34 & 1.34 \\
\hline Sweetened drinks frequency & 17 & 3.24 & 3.49 & 4 & 1.25 & 1.50 & 5 & 5.40 & 9.42 \\
\hline Tea and coffee frequency & 17 & 6.24 & 4.74 & 4 & 3.25 & 2.99 & 5 & 6.20 & 1.64 \\
\hline Desserts and snacks frequency & 17 & 2.82 & 2.38 & 4 & 1.50 & 1.29 & 5 & 1.80 & 1.3 \\
\hline Diet confidence & 17 & 2.65 & 1.37 & 4 & 2.25 & 0.96 & 5 & 2.40 & 0.89 \\
\hline Diet persistence & 17 & 2.94 & 1.25 & 4 & 2.50 & 1.00 & 5 & 2.20 & 0.84 \\
\hline Health internal locus of control & 17 & 3.77 & 0.45 & 4 & 3.34 & 0.78 & 5 & 3.80 & 0.27 \\
\hline Message helpfulness & - & - & - & 4 & 2.00 & 0.82 & 5 & 2.00 & 0.71 \\
\hline Health perception & - & - & - & 4 & 2.00 & 0.82 & 5 & 2.20 & 0.45 \\
\hline Food portion area & 9 & 269.97 & 113.72 & - & - & - & 6 & 263.62 & 99.2 \\
\hline \multicolumn{10}{|l|}{ Health consequences } \\
\hline BMI & 18 & 24.11 & 3.86 & 6 & 23.69 & 3.69 & 6 & 24.41 & 3.89 \\
\hline Waistline $(\mathrm{cm})$ & 17 & 80.80 & 11.72 & 5 & 78.26 & 11.44 & 6 & 78.73 & 10.78 \\
\hline Preferred food portion for consumption & 17 & 5.21 & 1.36 & 6 & 4.85 & 1.65 & 6 & 5.03 & 1.53 \\
\hline Sweetened drinks frequency & 18 & 3.61 & 4.10 & 5 & 1.80 & 1.92 & 6 & 2.67 & 1.21 \\
\hline Tea and coffee frequency & 18 & 3.50 & 2.46 & 5 & 3.40 & 2.51 & 6 & 1.83 & 1.83 \\
\hline Desserts and snacks frequency & 18 & 3.83 & 2.62 & 5 & 2.40 & 2.07 & 6 & 3.83 & 5.04 \\
\hline Diet confidence & 18 & 2.50 & 0.92 & 6 & 1.83 & 1.33 & 6 & 2.67 & 1.21 \\
\hline Diet persistence & 18 & 2.78 & 0.88 & 6 & 2.33 & 0.82 & 6 & 2.50 & 0.55 \\
\hline Health internal locus of control & 18 & 4.06 & 0.52 & 6 & 4.03 & 0.29 & 6 & 4.00 & 0.35 \\
\hline Message helpfulness & - & - & - & 6 & 2.67 & 0.52 & 6 & 2.83 & 1.17 \\
\hline Health perception & - & - & - & 6 & 2.33 & 0.82 & 6 & 3.00 & 1.10 \\
\hline Food portion area & 12 & 288.91 & 89.86 & - & - & - & 6 & 311.38 & 161.02 \\
\hline \multicolumn{10}{|l|}{ Behaviour substitution } \\
\hline BMI & 17 & 23.22 & 3.90 & 8 & 22.96 & 4.17 & 7 & 24.11 & 4.48 \\
\hline Waistline $(\mathrm{cm})$ & 17 & 80.26 & 11.45 & 8 & 81.86 & 16.06 & 7 & 81.05 & 15.99 \\
\hline Preferred food portion for consumption & 17 & 5.01 & 1.13 & 8 & 5.06 & 0.93 & 7 & 4.50 & 1.02 \\
\hline Sweetened drinks frequency & 16 & 6.00 & 11.32 & 8 & 6.38 & 9.30 & 7 & 1.57 & 2.07 \\
\hline
\end{tabular}




\begin{tabular}{|c|c|c|c|c|c|c|c|c|c|}
\hline Tea and coffee frequency & 16 & 4.13 & 4.98 & 8 & 4.75 & 4.46 & 7 & 4.43 & 5.26 \\
\hline Desserts and snacks frequency & 17 & 3.53 & 2.18 & 8 & 3.63 & 2.26 & 7 & 4.00 & 2.08 \\
\hline Diet confidence & 17 & 3.29 & 1.05 & 8 & 3.63 & 0.92 & 7 & 3.43 & 0.98 \\
\hline Diet persistence & 17 & 3.18 & 1.19 & 8 & 3.88 & 0.64 & 7 & 3.00 & 1.15 \\
\hline Health internal locus of control & 17 & 3.91 & 0.41 & 8 & 4.15 & 0.40 & 7 & 4.12 & 0.63 \\
\hline Message helpfulness & - & - & - & 8 & 3.00 & 1.31 & 7 & 3.57 & 1.51 \\
\hline Health perception & - & - & - & 8 & 3.25 & 1.04 & 7 & 3.29 & 1.38 \\
\hline Food portion area & 13 & 285.67 & 77.06 & - & - & - & 7 & 198.69 & 56.73 \\
\hline \multicolumn{10}{|l|}{ Social Comparison } \\
\hline BMI & 18 & 22.83 & 4.08 & 5 & 20.81 & 3.67 & 4 & 20.65 & 1.85 \\
\hline Waistline (cm) & 17 & 75.42 & 9.96 & 5 & 71.41 & 8.43 & 4 & 72.75 & 2.36 \\
\hline Preferred food portion for consumption & 17 & 5.13 & 1.38 & 5 & 4.70 & 1.17 & 4 & 6.36 & 1.53 \\
\hline Sweetened drinks frequency & 18 & 1.56 & 1.38 & 5 & 2.60 & 2.61 & 4 & 2.00 & 1.63 \\
\hline Tea and coffee frequency & 18 & 4.28 & 3.14 & 5 & 5.20 & 5.54 & 4 & 3.00 & 2.00 \\
\hline Desserts and snacks frequency & 18 & 2.83 & 1.34 & 5 & 4.80 & 2.28 & 4 & 2.50 & 1.73 \\
\hline Diet confidence & 18 & 2.39 & 0.85 & 5 & 3.00 & 0.71 & 4 & 2.50 & 0.58 \\
\hline Diet persistence & 18 & 3.17 & 1.15 & 5 & 2.80 & 0.84 & 4 & 2.50 & 0.58 \\
\hline Health internal locus of control & 18 & 4.12 & 0.41 & 5 & 4.23 & 0.65 & 4 & 4.21 & 0.81 \\
\hline Message helpfulness & - & - & - & 5 & 2.2 & 1.10 & 4 & 2.25 & 0.96 \\
\hline Health perception & - & - & - & 5 & 2.4 & 1.14 & 4 & 2.25 & 0.96 \\
\hline Food portion area & 11 & 392.31 & 259.69 & - & - & - & 6 & 313.85 & 87.72 \\
\hline
\end{tabular}

Table 3. Descriptive Statistics of Psychological Measures.

\begin{tabular}{|c|c|c|c|c|}
\hline & $n$ & $M$ & $S D$ & $\alpha$ \\
\hline \multicolumn{5}{|c|}{ Five-factor personality } \\
\hline Extraversion & 70 & 2.83 & 0.78 & .75 \\
\hline Agreeableness & 70 & 3.51 & 0.68 & .72 \\
\hline Conscientiousness & 70 & 3.28 & 0.65 & .51 \\
\hline Neuroticism & 70 & 2.86 & 0.8 & .77 \\
\hline Openness & 70 & 3.4 & 0.66 & .57 \\
\hline Perceived stress & 70 & 2.9 & 0.5 & .83 \\
\hline Narcissism & 70 & 2.91 & 1.25 & - \\
\hline \multicolumn{5}{|l|}{ Regulatory focus } \\
\hline Promotion & 70 & 3.28 & 0.65 & .51 \\
\hline Prevention & 70 & 2.86 & 0.8 & .77 \\
\hline \multicolumn{5}{|l|}{ Food choice motive } \\
\hline Health & 70 & 2.83 & 0.68 & .87 \\
\hline Weight control & 70 & 2.6 & 0.86 & .87 \\
\hline \multicolumn{5}{|l|}{ Three factor eating } \\
\hline Uncontrolled eating & 70 & 2.24 & 0.58 & .52 \\
\hline Cognitive restraint & 70 & 2.42 & 0.44 & .87 \\
\hline Emotional eating & 70 & 2.26 & 0.75 & .77 \\
\hline
\end{tabular}




\subsection{Comparison of Outcomes Measures}

Hypothesis 1: Individuals receiving nudge messages (all types) would have lower body measurements after intervention than before while those receiving control messages would have no difference.

In terms of body measurements (Table 4), the mean BMI and waistline were lower after the intervention period, for both "control" and "social comparison" conditions than before the intervention period. However, the mean BMI was higher for the "health consequences" condition after the intervention, even though the mean waistline was lower after intervention. Curiously, for the "behaviour substitution" condition, both the mean BMI and waistlines were higher after intervention. A two-way MANOVA did not reveal any significant differences in BMI and waistline across intervention time points (Pillais' Trace $=.02, F(4,200)=0.47, p>.05$ ), and between the four study conditions (Pillais' Trace $=.08$, $F(6,200)=1.34, p>.05)$ with no significant interaction effect, Pillais' Trace $=.07, F(12,200)$ $=0.86, p>.05$.

Hypothesis 2: Individuals receiving nudge messages (all types) would have improved food consumption behaviour after intervention than before while those receiving control messages would have no difference.

It was observed (Table 4) that, for the "control" condition, the mean preferred food portion for consumption, tea and coffee consumption, and desserts and snacks consumption were lower whereas the mean sweetened drinks consumption was higher after intervention. For the "health consequences" condition, the mean preferred food portion for consumption, sweetened drinks consumption, and tea and coffee consumption were lower whereas the mean desserts and snacks consumption remained unchanged after intervention. For the "behaviour substitution" condition, the mean preferred food portion, sweetened drinks consumption, and tea and coffee consumption were lower whereas the mean desserts and snacks consumption was higher after intervention. Lastly, for the "social comparison" condition, the mean preferred food portion and sweetened drinks consumption were both higher whereas the mean tea and coffee consumption, and desserts and snacks consumption were lower after intervention. A two-way MANOVA did not show significant main effect for study conditions, Pillais' Trace $=.13, F(12,282)=1.06, p>$ .05 , and intervention time points, Pillais' Trace $=.02, F(8,186)=0.19, p>.05$, while also did not show significant interaction effect, Pillais' Trace $=.19, F(24,380)=0.80, p>.05$.

Hypothesis 3: Individuals receiving nudge messages based on constructive encouragement would have higher diet confidence and diet persistence after intervention than before while those receiving messages based on fear, social pressure and those in the control condition would experience negligible differences.

For diet confidence and diet persistence (Table 4), the "control" condition participants had lower mean diet confidence and diet persistence after the intervention period than before, while in the case of the "health consequences", "behaviour substitution", and "social comparison" conditions, the mean diet confidence was higher whereas the mean diet persistence was lower (Table 4). A two-way MANOVA confirmed the significance of the main effect for the study conditions, with Pillais' Trace $=.17, F(6,206)=3.23, p<.05$, but there was no significant main effect between intervention time points, Pillais' Trace $=$ $.05, F(4,206)=1.26, p>.05$, nor any significant interaction effect, Pillais' Trace $=.09, F(12$, 206) $=0.81, p>.05$.

Participants in the "behaviour substitution" condition (i.e., constructive encouragement) reported the highest mean message helpfulness and health perception scores, followed by those in the "health consequences", "social comparison", and "control" conditions. A one-way MANOVA did not reveal significant differences between the study conditions for the two measures, Pillais' Trace $=.39, F(6,36)=1.43, p<.05$. 
Table 4. Mean Change in Outcome Measures Between Pre- and Post-intervention.

\begin{tabular}{lcccc}
\hline & \multicolumn{4}{c}{ Mean change (\%) } \\
\cline { 2 - 5 } & Control & $\begin{array}{c}\text { Health conse- } \\
\text { quences }\end{array}$ & $\begin{array}{c}\text { Behaviour sub- } \\
\text { stitution }\end{array}$ & $\begin{array}{c}\text { Social Compari- } \\
\text { son }\end{array}$ \\
\hline BMI & $-0.83(-3.60)$ & $0.30(1.24)$ & $0.89(3.83)$ & $-2.18(-9.55)$ \\
Waistline (cm) & $-4.11(-5.23)$ & $-2.07(-2.56)$ & $0.79(0.98)$ & $-2.67(-3.54)$ \\
Preferred food portion & $-0.03(-0.56)$ & $-0.18(-3.45)$ & $-0.51(-10.18)$ & $1.23(23.98)$ \\
Sweetened drinks frequency & $2.16(66.67)$ & $-0.94(-26.04)$ & $-4.43(-73.83)$ & $0.44(28.21)$ \\
Tea and coffee frequency & $-0.04(-0.64)$ & $-1.67(-47.71)$ & $-5.57(-55.7)$ & $-1.28(-29.91)$ \\
Desserts and snacks frequency & $-1.02(-36.17)$ & $0.00(0.00)$ & $0.47(13.31)$ & $-0.33(-11.66)$ \\
Diet confidence & $-0.25(-9.43)$ & $0.17(6.80)$ & $0.14(4.26)$ & $0.11(4.60)$ \\
Diet persistence & $-0.74(-25.17)$ & $-0.28(-10.07)$ & $-0.18(-5.66)$ & $-0.67(-21.14)$ \\
Health internal locus of control & $0.03(0.80)$ & $-0.06(-1.48)$ & $0.21(5.37)$ & $0.09(2.18)$ \\
Food portion area & $-6.35(-2.35)$ & $22.47(7.78)$ & $-86.98(-30.45)$ & $-78.46(-20.00)$ \\
\hline
\end{tabular}

\subsection{Relationship between Specific Outcome and Psychological Measures}

Pearson correlations were derived for specific pair of outcome and psychological measures at the pre-intervention time point (Table 5). Notably, for outcome measures, BMI had significant moderate positive correlation with the uncontrolled eating and emotional eating factors (Table 5). Preferred food portion had a significant but weak negative correlation between extraversion and uncontrolled eating and there was significant moderate negative correlation with agreeableness. Diet confidence had a significant, though weak, positive correlation with extraversion and conscientiousness as well as with diet persistence and had significant moderate positive correlation with health food choice motive. Lastly, the health internal locus of control had a significant but weak positive correlation with health and weight control food choice motive. For psychological measures, extraversion had a significant but weak positive relationship with uncontrolled eating. Health and weight control food choice motive have significant moderate positive relationship with cognitive restraint. 
Table 5. Correlation Matrix of Outcome and Psychological Measures at Pre-intervention.

\begin{tabular}{|c|c|c|c|c|c|c|c|c|c|c|c|c|c|c|c|c|c|}
\hline & 1 & 2 & 3 & 4 & 5 & 6 & 7 & 8 & 9 & 10 & 11 & 12 & 13 & 14 & 15 & 16 & 17 \\
\hline \multicolumn{18}{|l|}{ 1. BMI } \\
\hline $\begin{array}{l}\text { 2. Preferred food portion } \\
\text { for consumption }\end{array}$ & .00 & & & & & & & & & & & & & & & & \\
\hline 3. Diet confidence & -.19 & -.11 & & & & & & & & & & & & & & & \\
\hline 4. Diet persistence & -.07 & -.06 & $.50^{* *}$ & & & & & & & & & & & & & & \\
\hline 5. Health internal locus of control & -.01 & -.15 & .04 & .19 & & & & & & & & & & & & & \\
\hline \multicolumn{18}{|l|}{ Five factor personality } \\
\hline 6. Extraversion & .19 & $-.26^{*}$ & $.26^{*}$ & .11 & .06 & & & & & & & & & & & & \\
\hline 7. Agreeableness & .04 & $-.31^{*}$ & .10 & $.26^{*}$ & .16 & $.31^{* *}$ & & & & & & & & & & & \\
\hline 8. Conscientiousness & -.07 & -.09 & $.27^{*}$ & .10 & .10 & .08 & .22 & & & & & & & & & & \\
\hline 9. Neuroticism & -.12 & .03 & -.14 & -.13 & -.09 & -.17 & -.21 & $-.32^{* *}$ & & & & & & & & & \\
\hline 10. Openness & .06 & -.05 & -.09 & .06 & .02 & -.02 & .20 & -.03 & -.02 & & & & & & & & \\
\hline 11. Perceived stress & .06 & .03 & -.14 & -.09 & -.16 & -.21 & -.17 & $-.41^{* *}$ & $.66^{* *}$ & -.15 & & & & & & & \\
\hline \multicolumn{18}{|l|}{ Regulatory focus } \\
\hline 12. Promotion & .07 & -.08 & -.15 & .00 & .12 & .04 & .03 & -.17 & -.20 & $.54^{* *}$ & $-.27^{*}$ & & & & & & \\
\hline 13. Prevention & -.09 & .09 & -.19 & -.07 & .10 & .04 & $.25^{*}$ & -.01 & .06 & -.04 & -.08 & .06 & & & & & \\
\hline \multicolumn{18}{|l|}{ Food choice motive } \\
\hline 14. Health & .02 & .06 & .17 & $.31^{* *}$ & $.27^{*}$ & .12 & -.03 & .18 & -.05 & .00 & -.05 & .15 & .04 & & & & \\
\hline 15. Weight control & -.06 & .15 & .14 & .19 & $.28^{*}$ & -.02 & -.07 & .16 & -.08 & -.21 & -.05 & -.04 & .06 & $.64^{* *}$ & & & \\
\hline \multicolumn{18}{|l|}{ Three factor eating } \\
\hline 16. Uncontrolled eating & $.35^{* *}$ & $-.25^{*}$ & -0.2 & -.01 & .08 & $.24^{*}$ & .16 & -.14 & -.02 & -.07 & .17 & .08 & -.04 & -.11 & -.16 & & \\
\hline 17. Cognitive restraint & -.14 & .12 & .05 & .01 & .21 & .01 & -.05 & .13 & -.12 & -.23 & -.05 & .02 & .03 & $.33^{* *}$ & $.49^{* *}$ & .07 & \\
\hline 18. Emotional eating & $.35^{* *}$ & -.13 & -.08 & .06 & .06 & .20 & .14 & -.02 & .13 & -.02 & .23 & .06 & .01 & .08 & -.03 & $.74^{* *}$ & .08 \\
\hline
\end{tabular}

Note: ${ }^{*} p<.05,{ }^{* *} p<.01$

\section{Discussion}

We sought to examine the effects of administering various types of nudges ("health consequences", "behaviour substitution", "social comparison") through WhatsApp on various diet and health related measurements in this ambitious study that included investigating the psychological factors and perception of the participants. While the G*Power calculation required a minimum of 250 participants, we were only able to recruit 70 over the late Oct 2019 to early 2021 period. There was a significant number of incomplete submissions, leading to only 17 completed participants. Many factors contributed to this from the numerous items in the surveys and the high demand of participant attention to the ongoing COVID19 pandemic measures interrupting lives and the change in WhatsApp policy in January 2021 that resulted in many users ending their use of WhatsApp for other platforms. This change of events impact our initial utility of the WhatsApp app for its widespread use and successful utility in education [65,66] and in healthcare [67]. From the limited 17 participants, we did not find any significant effects of nudge messages nor within the various types on body measurements of BMI nor waistlines, food consumption behaviours, diet confidence and diet persistence, or perceived message helpfulness. Nonetheless, an in-depth investigation of the collected data provided insights to the use of nudges for food-related behaviours that may guide future studies.

We found an interesting decrease of BMI for the control and social comparison conditions, but it was reversed for health consequences and behaviour substitution conditions, and there was a waistline decrease across all measures with few exceptions (Table 
2). This finding suggests that being made self-conscious of the food eaten alone was able to elicit some effort of control by the people with the exceptions. These exceptions include the waistline for the behavioural substitution and the preferred food portions, sweetened drinks, and health internal locus of the social comparison condition. Taking together the BMI increase for health consequences and behaviour substitution and the decrease of waistline for the health consequences, the possibility of weight gain could be due to muscle mass gain (assumed from decreased waistline) from increased exercise. What is surprising is that the overall increase of snacks, and decreased diet persistence of behaviour substitution suggested that this form of intervention may not yield the desired effect and that with the assumption of muscle mass, fear in health consequences may have encouraged exercise and muscle gain better than the control and social comparison condition.

What was interesting in the social comparison condition was that despite it having the best decrease in BMI of $\sim 2.2$, its waistline decrease of $\sim 2.5 \mathrm{~cm}$ was less than the control of $\sim 4 \mathrm{~cm}$ (Table 4 ), yet its increase in preferred food consumption, sweetened drinks and decreased diet persistence may suggest practices of starvation that caused some compensation given the decrease in snacking frequency and second largest decrease in food portion at -78.5 after behaviour substation at -87. Social comparison methods may, at least in the short term, be the most effective intervention (in terms of highest increase in internal locus of control as well) for getting people to eat less and decrease their BMI.

Despite perceived stress shown to be associated with unhealthy dietary habits $[68,69]$ and weight gain [70], we did not find any correlation with BMI for the possible reason that the 21 days of this study was not likely to provide sufficient time for notable weight changes, as well as the small sample size. Even so, this was in agreement with some past studies $[68,71]$ that did not find such correlations. In addition, the study showed uncontrolled and emotional eating to have significant positive correlations with BMI affirming that diet plays the major role in increased BMI. We further found a weak negative correlation with preferred food portion regardless of whether it was healthy or unhealthy food that was contrary to a past study reporting a positive correlation between uncontrolled eating and food portion size [72]. This discrepancy may be explained by a compensation of more frequent consumption despite choosing smaller portions by the those with uncontrolled eating.

On psychological parameters, we found extraversion to have a weak negative correlation with preferred food portion which may support the above observation on uncontrolled eating given that a past study [73] reported that high extraversion individuals may consume more sweet and savoury food and sugary beverages. Thus, extraverts may in fact, consume smaller portions of food but in higher frequency.

\subsection{Limitations and Future Studies}

Due to the many tasks in this study, there was a $68.6 \%$ drop-out rate impacting the significance of the findings. Only $\sim 31.4 \%$ of the initial 70 participants completed all aspects of the study. Certainly, further investigations need to be utilized less parameters than what we have attempted here. Notably, given the lack of obvious associations of sociodemographic factors with the interventions, it may be possible to exclude these parameters as well as leaving out the need mid-point intervention given the general consistency with the end of intervention. Given that the control condition also saw a decrease, a better control that did not involve food at all may perhaps decrease awareness and reminders for a better baseline analysis. Given the problems with the instant messaging app, it may be possible that better convenience of data collection also in-built app nudges that also include steps taken and exercise logging e.g. APD Health Nudge app [74]. 


\section{Conclusion}

Our findings in this pilot study suggest the mere awareness of food intake can have an effect in eating habits with potential effectiveness in the use of fear and social comparison nudges for food-related behaviours and exercise across the multi-cultural background while reaffirming the suitability of BMI together with waistlines in more objective measurements, even within the 23-day experiment. Certainly, the use of apps is feasible, although further adaptions for the ease of use would reduce participation drop-off.

Supplementary Materials: The following are available online at www.mdpi.com/xxx/s1, Table S1: Survey Instructions and Question Items (Data Collection Form), Table S2: Study Procedure Instructions, Table S3: List of Behavioral Change Messages.

Author Contributions: Conceptualization, S.K.-E.G.; methodology, K.-S.W., S.K.-E.G. and C.S.-L.T.; software, K.-F.C.; formal analysis, K.-S.W., B.J.-K.C., J.Y.Y. and S.K.-E.G.; investigation, B.J.-K.C.; writing-original draft preparation, K.-S.W., S.K.-E.G., B.-K.Q.; writing-review and editing, B.K.Q. and S.K.-E.G.; supervision, S.K.-E.G. All authors have read and agreed to the published version of the manuscript.

Funding: This research was partially funded by the Science \& Engineering Research Council (SERC) Strategic Funds from the Agency for Science, Technology, and Research (A*STAR).

Institutional Review Board Statement: The study was conducted according to the guidelines of the Declaration of Helsinki, and approved by the Institutional Review Board (or Ethics Committee) of the Agency of Science, Technology and Research (A*STAR IRB; reference number: 2019-007).

Informed Consent Statement: Informed consent was obtained from all subjects involved in the study.

Data Availability Statement: The data presented in this study are available on request from the corresponding author.

Acknowledgments: The authors would like to thank Thai Shawn for the initial assistance with the IRB form for submission.

Conflicts of Interest: The authors declare no conflict of interest.

\section{References}

1. Earl, P.E. Richard H. Thaler: A Nobel Prize for Behavioural Economics. Review of Political Economy 2018, 30, 107-125, doi:10.1080/09538259.2018.1513236.

2. Thaler, R.H.; Ganser, L. Misbehaving: The making of behavioral economics; W. W. Norton \& Company: New York, 2015.

3. Pavlov, I.P.; Thompson, W.H. The work of the digestive glands; C. Griffin: London, 1910.

4. Carew, T.J.; Pinsker, H.M.; Kandel, E.R. Long-term habituation of a defensive withdrawal reflex in aplysia. Science 1972, 175, 451-454, doi:10.1126/science.175.4020.451.

5. Stafford, T.F. Conscious and Unconscious Processing of Priming Cues in Selling Encounters. Journal of Personal Selling $\mathcal{E}$ Sales Management 1996, 16, 37-44, doi:10.1080/08853134.1996.10754052.

6. Junger, M.; Montoya, L.; Overink, F.J. Priming and warnings are not effective to prevent social engineering attacks. Computers in Human Behavior 2017, 66, 75-87, doi:10.1016/j.chb.2016.09.012.

7. Winberg, M. Can You Hear It? Sonic Devices Play High-Pitched Noises To Repel Teens. Available online: https://www.npr.org/2019/07/10/739908153/can-you-hear-it-sonic-devices-play-high-pitched-noises-to-repel-teens (accessed on 06 September 2021).

8. Matsubayashi, T.; Sawada, Y.; Ueda, M. Does the installation of blue Lights on train platforms shift suicide to another station?: Evidence from Japan. Journal of Affective Disorders 2014, 169, 57-60, doi:10.1016/j.jad.2014.07.036.

9. Benartzi, S.; Beshears, J.; Milkman, K.L.; Sunstein, C.R.; Thaler, R.H.; Shankar, M.; Tucker-Ray, W.; Congdon, W.J.; Galing, S. Should Governments Invest More in Nudging? Psychological Science 2017, 28, 1041-1055, doi:10.1177/0956797617702501.

10. Halpern, D.; Sanders, M. Nudging by government: Progress, impact, \& lessons learned. Behavioral Science E Policy 2016, 2, 5265, doi:10.1353/bsp.2016.0015.

11. Tannenbaum, M.B.; Hepler, J.; Zimmerman, R.S.; Saul, L.; Jacobs, S.; Wilson, K.; Albarracín, D. Appealing to fear: A metaanalysis of fear appeal effectiveness and theories. Psychol Bull 2015, 141, 1178-1204, doi:10.1037/a0039729.

12. Dillard, J.P.; Li, R.; Huang, Y. Threat Appeals: The Fear-Persuasion Relationship is Linear and Curvilinear. Health Communication 2017, 32, 1358-1367, doi:10.1080/10410236.2016.1220345.

13. Moussaoui, L.S.; Claxton, N.; Desrichard, O. Fear appeals to promote better health behaviors: an investigation of potential mediators. Health Psychology and Behavioral Medicine 2021, 9, 600-618, doi:10.1080/21642850.2021.1947290. 
14. Orji, R.; Mandryk, R.L. Developing culturally relevant design guidelines for encouraging healthy eating behavior. International Journal of Human-Computer Studies 2014, 72, 207-223, doi:10.1016/j.ijhcs.2013.08.012.

15. Orji, R. Why Are Persuasive Strategies Effective? Exploring the Strengths and Weaknesses of Socially-Oriented Persuasive Strategies. Cham, 2017; pp. 253-266.

16. O'Keefe, D.J.; Jensen, J.D. The Relative Persuasiveness of Gain-Framed Loss-Framed Messages for Encouraging Disease Prevention Behaviors: A Meta-Analytic Review. Journal of Health Communication 2007, 12, 623-644, doi:10.1080/10810730701615198.

17. Gan, S.K.-E.; Lim, K.M.-J.; Haw, Y.-X. The relaxation effects of stimulative and sedative music on mathematics anxiety: A perception to physiology model. Psychology of Music 2016, 44, 730-741, doi:10.1177/0305735615590430.

18. Chew, A.S.-Q.; Yu, Y.-T.; Chua, S.-W.; Gan, S.K.-E. The effects of familiarity and language of background music on working memory and language tasks in Singapore. Psychology of Music 2016, 44, 1431-1438, doi:10.1177/0305735616636209.

19. Choo, B.J.-K.; Cheok, T.-S.; Gunasegaran, D.; Wan, K.-S.; Quek, Y.-S.; Tan, C.S.-L.; Quek, B.-K.; Gan, S.K.-E. The sound of music on the pocket: A study of background music in retail. Psychology of Music 2020, 0, 0305735620958472, doi:10.1177/0305735620958472.

20. Neal, D.; Vujcic, J.; Burns, R.; Wood, W.; Devine, J. Nudging and habit change for open defecation: new tactics from behavioral science. World Bank, Water and Sanitation Program 2016.

21. Colasante, A.; D'Adamo, I.; Morone, P. Nudging for the increased adoption of solar energy? Evidence from a survey in Italy. Energy Research \& Social Science 2021, 74, 101978, doi:10.1016/j.erss.2021.101978.

22. Weijers, R.J.; de Koning, B.B.; Paas, F. Nudging in education: from theory towards guidelines for successful implementation. European Journal of Psychology of Education 2021, 36, 883-902, doi:10.1007/s10212-020-00495-0.

23. Blumenthal-Barby, J.S.; Burroughs, H. Seeking Better Health Care Outcomes: The Ethics of Using the "Nudge". The American Journal of Bioethics 2012, 12, 1-10, doi:10.1080/15265161.2011.634481.

24. Reisch, L.A.; Sunstein, C.R.; Gwozdz, W. Viewpoint: Beyond carrots and sticks: Europeans support health nudges. Food Policy 2017, 69, 1-10, doi:10.1016/j.foodpol.2017.01.007.

25. Matjasko, J.L.; Cawley, J.H.; Baker-Goering, M.M.; Yokum, D.V. Applying Behavioral Economics to Public Health Policy: Illustrative Examples and Promising Directions. American Journal of Preventive Medicine 2016, 50, S13-S19, doi:10.1016/j.amepre.2016.02.007.

26. Patel, M.S. Nudges for influenza vaccination. Nature Human Behaviour 2018, 2, 720-721, doi:10.1038/s41562-018-0445-x.

27. Rigtering, C.; Weitzel, U. Corporate Nudging and Employee Idea Development. Academy of Management Proceedings 2016, 2016, 16368, doi:10.5465/ambpp.2016.16368abstract.

28. Dai, H.; Saccardo, S.; Han, M.A.; Roh, L.; Raja, N.; Vangala, S.; Modi, H.; Pandya, S.; Sloyan, M.; Croymans, D.M. Behavioural nudges increase COVID-19 vaccinations. Nature 2021, doi:10.1038/s41586-021-03843-2.

29. Gan, S.K.-E.; Loh, C.; Seet, B. Hypertension in Young Adults - An Under-Estimated Problem. Singapore medical journal 2003, 44, 448-452.

30. Field, A.E.; Coakley, E.H.; Must, A.; Spadano, J.L.; Laird, N.; Dietz, W.H.; Rimm, E.; Colditz, G.A. Impact of Overweight on the Risk of Developing Common Chronic Diseases During a 10-Year Period. Archives of Internal Medicine 2001, 161, 1581-1586, doi:10.1001/archinte.161.13.1581.

31. Grundy, S.M. Obesity, Metabolic Syndrome, and Cardiovascular Disease. The Journal of Clinical Endocrinology E Metabolism 2004, 89, 2595-2600, doi:10.1210/jc.2004-0372.

32. Poirier, P.; Giles, T.D.; Bray, G.A.; Hong, Y.; Stern, J.S.; Pi-Sunyer, F.X.; Eckel, R.H. Obesity and Cardiovascular Disease. Arteriosclerosis, Thrombosis, and Vascular Biology 2006, 26, 968-976, doi:doi:10.1161/01.ATV.0000216787.85457.f3.

33. Lobstein, T.; Jackson-Leach, R. Planning for the worst: estimates of obesity and comorbidities in school-age children in 2025. Pediatric Obesity 2016, 11, 321-325, doi:10.1111/ijpo.12185.

34. Lai, L. Singapore at risk of becoming fat nation. The New Paper 2017.

35. Health Promotion Board. Report of the National Nutrition Survey 2010; 2010.

36. Health Promotion Board. National Nutrition Survey 2018 Shows Gradual Improvements in Singaporeans' Dietary Habits. Available online: https://www.hpb.gov.sg/article/national-nutrition-survey-2018-shows-gradual-improvements-in-singaporeansdietary-habits (accessed on 06 September 2021).

37. Khalik, S. Salt and sugar intake way too high, but fruit and vegetable consumption improving: HPB survey. The Straits Times 2018.

38. Thaler, R.H.; Sunstein, C.R. Nudge: Improving decisions about health, wealth, and happiness; New Haven: Yale University Press: 2008.

39. Broers, V.J.V.; De Breucker, C.; Van den Broucke, S.; Luminet, O. A systematic review and meta-analysis of the effectiveness of nudging to increase fruit and vegetable choice. European Journal of Public Health 2017, 27, 912-920, doi:10.1093/eurpub/ckx085.

40. Cadario, R.; Chandon, P. Which Healthy Eating Nudges Work Best? A Meta-Analysis of Field Experiments. Marketing Science 2020, 39, 465-486, doi:10.1287/mksc.2018.1128.

41. Michie, S.; Abraham, C.; Whittington, C.; McAteer, J.; Gupta, S. Effective techniques in healthy eating and physical activity interventions: a meta-regression. Health psychology 2009, 28, 690.

42. Hartmann-Boyce, J.; Johns, D.J.; Jebb, S.A.; Aveyard, P.; Group, B.W.M.R. Effect of behavioural techniques and delivery mode on effectiveness of weight management: systematic review, meta-analysis and meta-regression. Obesity Reviews 2014, 15, 598-609, doi:10.1111/obr.12165.

43. Gan, S.K.-E.; Yeo, J.Y. Editorial: The promises of Microcontroller kits and Smartphone apps for Psychological research. Scientific Phone Apps and Mobile Devices 2020, 6, doi:10.30943/2020/06022020. 
44. Gan, S.K.-E. Editorial: "Set My Scientists Free" - Scientific Phone Apps and DIY equipment during lockdowns. Scientific Phone Apps and Mobile Devices 2020, 6, 1-3, doi:10.30943/2020/14042020.

45. Liu, J.J.W.; Gervasio, J.; Reed, M. Digitizing resilience: Feasibility of mobile applications for psychological research. Scientific Phone Apps and Mobile Devices 2020, 6, doi:10.30943/2020/15012020.

46. Liew, K.-C.; Kui, K.; Wu, W.; Gan, S.K.-E. Application Notes: PsychVey Ver2 - Improving online survey data collection. Scientific Phone Apps and Mobile Devices 2020, 6, doi:10.30943/2020/16092020.

47. Free, C.; Knight, R.; Robertson, S.; Whittaker, R.; Edwards, P.; Zhou, W.; Rodgers, A.; Cairns, J.; Kenward, M.G.; Roberts, I. Smoking cessation support delivered via mobile phone text messaging (txt2stop): a single-blind, randomised trial. The Lancet 2011, 378, 49-55, doi:10.1016/S0140-6736(11)60701-0.

48. Herbert, L.; Owen, V.; Pascarella, L.; Streisand, R. Text Message Interventions for Children and Adolescents with Type 1 Diabetes: A Systematic Review. Diabetes Technology \& Therapeutics 2013, 15, 362-370, doi:10.1089/dia.2012.0291.

49. Stephens, J.; Allen, J. Mobile Phone Interventions to Increase Physical Activity and Reduce Weight: A Systematic Review. Journal of Cardiovascular Nursing 2013, 28, doi:10.1097/JCN.0b013e318250a3e7.

50. Ng, R.Y.-X.; Wong, Y.-S.; Yeo, J.-Y.; Koh, C.L.-Z.; Wilson, C.; Ken-En Gan, S. The associations between dietary practices and dietary quality, biological health indicators, perceived stress, religiosity, culture, and gender in multicultural Singapore. Journal of Ethnic Foods 2018, 5, 220-227, doi:10.1016/j.jef.2018.07.003.

51. Bobek, D.D.; Roberts, R.W.; Sweeney, J.T. The Social Norms of Tax Compliance: Evidence from Australia, Singapore, and the United States. Journal of Business Ethics 2007, 74, 49-64, doi:10.1007/s10551-006-9219-x.

52. Puchniak, D.W.; Lan, L.L. Independent Directors in Singapore: Puzzling Compliance Requiring Explanationt. The American Journal of Comparative Law 2017, 65, 265-333, doi:10.1093/ajcl/avx023.

53. Wong, C.M.L.; Jensen, O. The paradox of trust: perceived risk and public compliance during the COVID-19 pandemic in Singapore. Journal of Risk Research 2020, 23, 1021-1030, doi:10.1080/13669877.2020.1756386.

54. Michie, S.; van Stralen, M.M.; West, R. The behaviour change wheel: A new method for characterising and designing behaviour change interventions. Implementation Science 2011, 6, 42, doi:10.1186/1748-5908-6-42.

55. Michie, S.; Richardson, M.; Johnston, M.; Abraham, C.; Francis, J.; Hardeman, W.; Eccles, M.P.; Cane, J.; Wood, C.E. The Behavior Change Technique Taxonomy (v1) of 93 Hierarchically Clustered Techniques: Building an International Consensus for the Reporting of Behavior Change Interventions. Annals of Behavioral Medicine 2013, 46, 81-95, doi:10.1007/s12160-013-9486-6.

56. Brunstrom, J.M.; Shakeshaft, N.G.; Scott-Samuel, N.E. Measuring 'expected satiety' in a range of common foods using a method of constant stimuli. Appetite 2008, 51, 604-614, doi:10.1016/j.appet.2008.04.017.

57. Wallston, K.A.; Strudler Wallston, B.; DeVellis, R. Development of the Multidimensional Health Locus of Control (MHLC) Scales. Health Education Monographs 1978, 6, 160-170, doi:10.1177/109019817800600107.

58. Donnellan, M.B.; Oswald, F.L.; Baird, B.M.; Lucas, R.E. The Mini-IPIP Scales: Tiny-yet-effective measures of the Big Five Factors of Personality. Psychological Assessment 2006, 18, 192-203, doi:10.1037/1040-3590.18.2.192.

59. Cohen, S.; Kamarck, T.; Mermelstein, R. A Global Measure of Perceived Stress. Journal of Health and Social Behavior 1983, 24, 385-396, doi:10.2307/2136404.

60. Konrath, S.; Meier, B.P.; Bushman, B.J. Development and Validation of the Single Item Narcissism Scale (SINS). PLOS ONE 2014, 9, e103469, doi:10.1371/journal.pone.0103469.

61. Fellner, B.; Holler, M.; Kirchler, E.; Schabmann, A. Regulatory Focus Scale (RFS): Development of a scale to record dispositional regulatory focus. Swiss Journal of Psychology / Schweizerische Zeitschrift für Psychologie / Revue Suisse de Psychologie 2007, 66, 109-116, doi:10.1024/1421-0185.66.2.109.

62. Steptoe, A.; Pollard, T.M.; Wardle, J. Development of a Measure of the Motives Underlying the Selection of Food: the Food Choice Questionnaire. Appetite 1995, 25, 267-284, doi:10.1006/appe.1995.0061.

63. Karlsson, J.; Persson, L.O.; Sjöström, L.; Sullivan, M. Psychometric properties and factor structure of the Three-Factor Eating Questionnaire (TFEQ) in obese men and women. Results from the Swedish Obese Subjects (SOS) study. International Journal of Obesity 2000, 24, 1715-1725, doi:10.1038/sj.ijo.0801442.

64. Wu, W.; Kenneth, Y.-W.; Budianto, I.; Gan, S.K.-E. Application Notes on APD AreametricApp: Automated area quantification for both Android and iOS. 2019, 2, doi:10.30943/2019/08022019.

65. Bouhnik, D.; Deshen, M. WhatsApp Goes to School: Mobile Instant Messaging between Teachers and Students. Journal of Information Technology Education: Research 2014, 13, 217-231, doi:10.28945/2051.

66. Gon, S.; Rawekar, A. Effectivity of E-Learning through Whatsapp as a Teaching Learning Tool. MVP Journal of Medical Sciences 2017, 4, 19, doi:10.18311/mvpjms/0/v0/i0/8454.

67. Kamel Boulos, M.N.; Giustini, D.M.; Wheeler, S. Instagram and WhatsApp in Health and Healthcare: An Overview. Future Internet 2016, 8, 37, doi:10.3390/fi8030037.

68. Barrington, W.E.; Ceballos, R.M.; Bishop, S.K.; McGregor, B.A.; Beresford, S.A. Perceived stress, behavior, and body mass ind ex among adults participating in a worksite obesity prevention program, Seattle, 2005-2007. Preventing Chronic Disease 2012, 9, E152, doi:10.5888/pcd9.120001.

69. Cartwright, M.; Wardle, J.; Steggles, N.; Simon, A.E.; Croker, H.; Jarvis, M.J. Stress and dietary practices in adolescents. Health Psychology 2003, 22, 362-369, doi:10.1037/0278-6133.22.4.362.

70. Block, J.P.; He, Y.; Zaslavsky, A.M.; Ding, L.; Ayanian, J.Z. Psychosocial Stress and Change in Weight Among US Adults. American Journal of Epidemiology 2009, 170, 181-192, doi:10.1093/aje/kwp104. 
71. Shimanoe, C.; Hara, M.; Nishida, Y.; Nanri, H.; Otsuka, Y.; Nakamura, K.; Higaki, Y.; Imaizumi, T.; Taguchi, N.; Sakamoto, T.; et al. Perceived Stress and Coping Strategies in Relation to Body Mass Index: Cross-Sectional Study of 12,045 Japanese Men and Women. PLOS ONE 2015, 10, e0118105, doi:10.1371/journal.pone.0118105.

72. Spence, M.; Stancu, V.; Dean, M.; Livingstone, M.B.E.; Gibney, E.R.; Lähteenmäki, L. Are food-related perceptions associated with meal portion size decisions? A cross-sectional study. Appetite 2016, 103, 377-385, doi:10.1016/j.appet.2016.04.039.

73. Keller, C.; Siegrist, M. Does personality influence eating styles and food choices? Direct and indirect effects. Appetite 2015, 84, 128-138, doi:10.1016/j.appet.2014.10.003.

74. APD Lab. APD Health Nudge app Beta. 2019, Android. 